\title{
Does Inequality Beget Inequality? Experimental Tests of the Prediction that Inequality Increases System Justification Motivation
}

\author{
Kris-Stella Trump* and Ariel White ${ }^{\dagger}$
}

\begin{abstract}
Past research shows that growing inequality often does not result in citizen demands for redistribution. We examine one mechanism that could explain why people do not protest growing inequality: a particular sub-prediction of system justification theory (SJT). SJT argues that humans have a psychological need to justify their social system. The specific subprediction of SJT tested here is the idea that inequality itself increases system justification. This could yield a negative feedback loop in which political responses to inequality grows ever less likely as inequality grows more extreme. Previous research on this hypothesis relied on cross-sectional survey data and provided mixed results. We take an experimental approach and ask whether exposure to economic inequality makes people more likely to defend the system. In one main study and two replications with varying samples, experimental treatments, and outcome measures, we find no evidence that information about economic inequality increases system justification motivation.
\end{abstract}

Keywords: Inequality, system justification, income inequality, cognitive dissonance

\section{INTRODUCTION}

Income inequality in the United States and many other countries has been increasing (Mishel and Finio, 2013; Saez, 2013), with little corresponding

For helpful comments, we thank Erin Hennes, Connor Huff, Aaron Kay, Martin Day, Thomas Leeper, the editors and anonymous reviewers of TESS, participants in the 2015 Aage Sørenson Memorial Conference, 2015 APSA Political Psychology Pre-conference, and the 2014 International Society for Justice Research Conference. Ariel White acknowledges support from the Harvard Center for American Political Studies and the Harvard Multidisciplinary Program in Inequality \& Social Policy. The data and code required to replicate all analyses in this article are available at the Journal of Experimental Political Science Dataverse within the Harvard Dataverse Network, at: doi:10.7910/DVN/SWV9GJ.

* Social Science Research Council, 300 Cadman Plaza West, 15th Fl., Brooklyn, NY 11201, USA, e-mail: trump@ssrc.org

${ }^{\dagger}$ Department of Political Science, Massachusetts Institute of Technology, 77 Massachusetts Avenue E53470, Cambridge, MA 02142, USA, e-mail: arwhi@mit.edu

(C) The Experimental Research Section of the American Political Science Association 2018 
movement in public demands for redistribution. Despite theoretical expectations that increasing inequality should lead to redistributive pressure (Meltzer and Richard, 1981), the literature provides many empirical examples to the contrary. ${ }^{1}$ In response to evidence that popular reactions to growing inequality have been mixed, recent contributions to the literature have explored the conditions under which demand for redistribution is more likely to occur (Franko, 2016; McCall, 2016; McCall et al., 2017), and the psychological (Johnson and Fujita, 2012; Day and Fiske, 2017) and socio-economic (Franko, 2017) variables that may be responsible for the patterns we observe. Scholarly debate continues about the specific mechanisms by which demand for redistribution does (not) emerge in response to increasing inequality.

In this paper, we focus on one specific mechanism that could explain why we observe political inaction in the face of growing inequality. In particular, we test a sub-prediction of system justification theory (SJT) (Jost et al., 2004; Jost and Banaji, 1994). System justification theory posits that individuals are motivated to legitimize existing social arrangements, "even at the expense of personal and group interest" (Jost and Banaji, 1994, p. 2). System justification theory has been used to explain the prevalence of numerous attitudes that do not seem to serve the selfinterest of the individual or their group (Laurin et al., 2010; Wakslak and Bauer, 2011; Brescoll et al., 2013), including attitudes toward economic inequality (Jost et al., 2004).

The specific sub-prediction of system justification theory that we focus on is the hypothesis that inequality itself can produce or exacerbate the system justification motivation (SJM) (Jost et al., 2004, 2003; Jost and Banaji, 1994). For conciseness, we call this prediction the "inequality-induced motivation hypothesis" throughout the paper. This hypothesis predicts that just experiencing or being aware of inequality will make people more motivated to justify their social, political, or economic systems.

This prediction builds on cognitive dissonance theory: the more people are disadvantaged by a system, the more starkly their experience of being disadvantaged contrasts with their motivation to believe that the system is just, and the more they therefore engage in system justification. On the individual level, this hypothesis implies that disadvantaged individuals exhibit higher levels of system justification than advantaged individuals (Jost et al. 2004, p. 909, Hypothesis 17). Aggregated to the society level, this hypothesis implies that we should observe more system justification in more unequal societies (Jost et al. 2004, p. 910, Hypothesis 18). This inequality-induced motivation hypothesis is thus an application of system justification theory to the specific question of what happens when there is more or less social and economic inequality in a society. In this paper, we test the inequalityinduced motivation hypothesis in the context of economic inequality. In particular,

\footnotetext{
${ }^{1}$ See, for example, Alesina and Glaeser (2004), Kelly and Enns (2010), Kenworthy and McCall (2008), Luttig (2013), McCall (2013), Schröder (2017), Trump (2017).
} 
we ask whether presenting realistic information about inequality to respondents results in increased system justification.

The prediction we test is different from the expectation that system justification influences how people react to inequality (which is a key prediction of SJT, but not one we test in this paper). The inequality-induced motivation hypothesis goes further: it posits that exposure to inequality can increase the SJM, i.e., as inequality increases, people become even more likely to react with motivated reasoning, and to see their system as fair.

If the inequality-induced motivation hypothesis is true, it could explain why increasing income inequality does not usually result in public dissatisfaction with inequality. As such, finding evidence in favor of this hypothesis would make a contribution to the broader literature on public responses to inequality, and the ongoing exploration of mechanisms that explain these responses. It would also yield further political predictions for the future, as it would suggest that inequality would tend to bring about even more inequality (as citizens became less and less likely to object to inequality due to system justification).

Thus far, the evidence for the inequality-induced motivation hypothesis has been observational, and has reached contradictory conclusions. Jost et al. (2003) find that "members of disadvantaged groups sometimes support and justify the social order to an even greater degree than members of advantaged groups do" (p.14). However, Brandt (2013) finds no support for this hypothesis using crossnational survey data. To the best of our knowledge, an experimental test of this hypothesis has never been published. In this paper, we experimentally test it by directly manipulating respondents' perceptions of inequality.

We provide respondents with information about income inequality in the United States, and then measure their levels of SJM. Across several types of informational treatments and multiple measures of system justification, in one nationally representative sample and several convenience samples, we find no evidence for the hypothesis that inequality increases the SJM. Our null results are precisely estimated and not due to a lack of statistical power. Political nonresponsiveness to inequality may be explained by many mechanisms (including system justification). But in this paper, we find no evidence that inequality-induced system justification is one of them.

\section{HYPOTHESIS}

We empirically evaluate two predictions derived from system justification theory (Jost et al. 2004, pp. 909-910). We first evaluate the hypothesis (H1) that higher inequality causes higher system justification.

Second, we look for evidence that would be consistent with the individual-level, cognitive dissonance based mechanism by which $\mathrm{H} 1$ is expected to occur. $\mathrm{H} 1$ is 
predicated on cognitive dissonance resulting from a combination of observing inequality and wanting to believe the world is just. Therefore, this effect is expected to be the strongest among disadvantaged individuals, for whom the contrast between their own disadvantage and the supposed fairness of the system is strongest. Our second hypothesis (H2) is therefore that we should observe a larger effect of inequality on system justification among disadvantaged respondents.

\section{METHODS AND RESULTS}

\section{Study Details}

We conducted ${ }^{2}$ a nationally representative online survey experiment through the GfK (formerly Knowledge Networks) panel in December 2014-January 2015. ${ }^{3}$ A total of 1,020 participants were allocated to one of the six groups (one of the two treatment groups, then one of the three outcome variables).

\section{Design}

The experimental design went through rigorous pre-fielding peer review as part of the funding process. The final research proposal, which includes power analyses and hypotheses, is available online at http://www.tessexperiments.org/data/trump605. $\mathrm{html}$ and thus serves as a form of pre-registration. ${ }^{4}$

Our main experimental treatment exposed participants to information about economic inequality. We showed participants one popular measure of income inequality: the Gini coefficient, which has been increasing relatively steadily in the United States since the 1970s. All participants in our study were exposed to accurate information about the Gini coefficient over the period 1968-2010, graphed in a similar way (data from Solt, 2009). However, they were randomly assigned to one of two different conditions. In the "low-inequality" or "control" treatment condition, the $y$-axis was set from 0 to 100 such that the trend looked relatively flat, while in the "high-inequality" treatment condition the $y$-axis was truncated to make the upward trend appear much steeper (see Figure 1). $Y$-axis truncation is a common and effective means of creating deceptive visualizations (Pandey et al., 2015), and has previously been used to generate treatments that successfully increase SJM (Kay et al., 2009).

\footnotetext{
${ }^{2}$ The experiment was funded by Time-Sharing Experiments for the Social Sciences (TESS) Grant number 605.

${ }^{3}$ Knowledge Networks maintains an online panel of participants; in order to ensure representativeness, recruited individuals who do not have an internet connection at home are provided with an internet connection. The participants are compensated for taking part in GfK surveys. For more detail on GfK, see http://www.knowledgenetworks.com/. GfK calculates survey weights and the representativeness of the sample by using the following variables: age, gender, race, Hispanic identity, education, Census region, household income, home ownership, metropolitan area, and internet access.

${ }^{4}$ This study was also approved by Harvard University's IRB.
} 

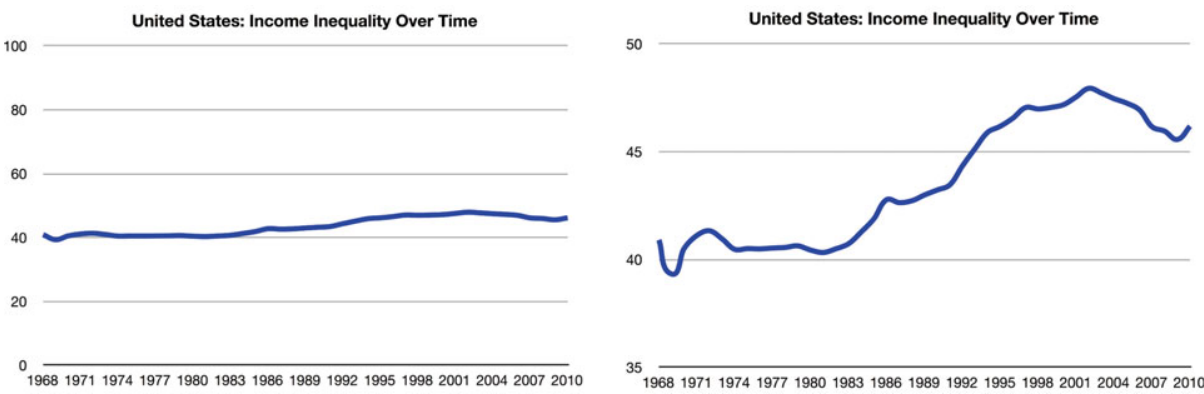

0 $1 9 6 \longdiv { 1 9 7 1 1 9 7 4 1 9 7 7 1 9 8 0 1 9 8 3 1 9 8 6 1 9 8 9 1 9 9 2 1 9 9 5 1 9 9 8 2 0 0 1 2 0 0 4 2 0 0 7 2 0 1 0 }$ Figure 1

The Treatment and Control Conditions.

Accompanying text read: "The line in the graph below shows the Gini coefficient, which is a measure of income differences. Higher numbers mean that the very rich have a higher share of total income." The left panel shows the control condition, where the increase of the Gini coefficient over time looks moderate. The right panel shows the treatment condition, where the same increase looks much larger.

We randomly assigned each respondent to answer one of three system justification measures, all drawn from prior literature on the subject. The first outcome measure was a system justification scale (Kay and Jost, 2003; Jost and Kay, 2005) where participants indicated their agreement or disagreement (on a ninepoint scale) with eight statements ${ }^{5}$ regarding the fairness of the overall social system of the United States. The items formed a reliable scale (Cronbach's $\alpha=0.88$ ), and we refer to it as the SJM measure.

Our second measure uses institutional trust questions, as in Brandt (2013). These questions ask the participants to indicate how much confidence ("A great deal," "Only some," or "Hardly any") they have in the people running the following institutions: the military, major companies, banks and financial institutions, the executive branch of the federal government, the United States Supreme Court, and Congress. Averaging across respondents' trust in the six institutions resulted in a scale with Cronbach's $\alpha=0.74$, and we refer to this as the "institutional trust" measure.

Finally, we include a slightly compressed version of a system justification scale that directly measures legitimation of the system in the economic realm: the economic system justification scale $(\alpha=0.78)$ (Jost and Thompson, 2000). ${ }^{6} \mathrm{We}$ will refer to it as the economic SJM measure. For ease of interpretation, we rescale all three measures to a $0-1$ scale.

\footnotetext{
${ }^{5}$ Items were as follows: "In general, you find society to be fair," "In general, the American political system operates as it should," "American society needs to be radically restructured" (reverse-scored), "The United States is the best country in the world to live in," "Most policies serve the greater good," "Everyone has a fair shot at wealth and happiness," "Our society is getting worse every year" (reversescored), and "Society is set up so that people usually get what they deserve."

${ }^{6}$ The individual items are available in the Supplementary Information. Due to survey length constraints, we used a reduced version of the 17-item Economic System Justification Scale. We omit two of the 17 items on the original scale based on their similarity to other items. Reduced versions of this scale have previously been used successfully, for example in Jost et al. (2003).
} 


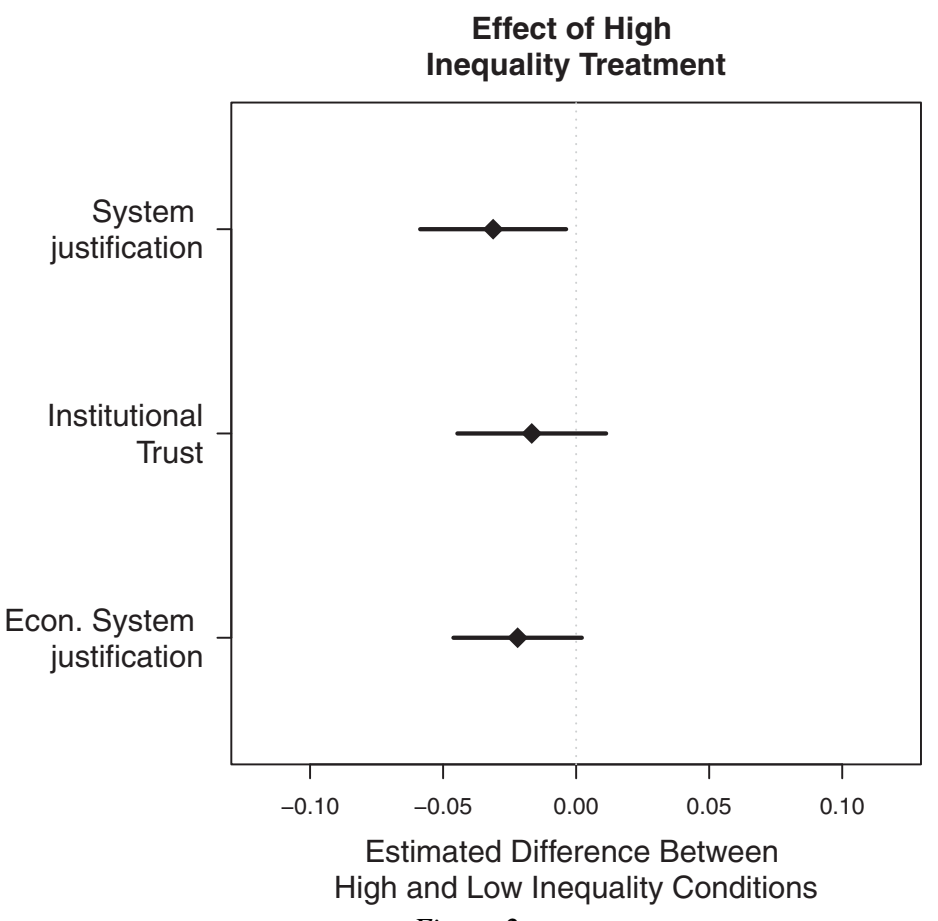

Figure 2

Estimated Effects of the "High Income Inequality" Treatment, Compared to "Low Inequality" / Control, on System Justification Measured in Three Ways (System Justification Scale, Institutional Trust Measure, and Economic System Justification Scale).

The effects are estimates based on $t$-tests, shown with their $95 \%$ confidence intervals. All outcome variables have been re-scaled to a $0-1$ scale. Positive effect estimates would indicate that system justification was higher in the "high inequality" treatment condition.

\section{Results}

We find no evidence that information about increasing economic inequality in the United States increases the respondents' SJM.

Before presenting the results in more detail, we pause to give a brief overview of the data, focusing in particular on the power we obtain in this study. The study is powered to detect an experimental treatment effect of 0.3 standard deviations. This means that after rescaling all outcome variables to a $0-1$ scale, we are powered to detect experimental treatment effects of 0.04 (SJM), 0.04 (institutional trust), and 0.03 (economic SJM), respectively. In our estimate, therefore, this study is sufficiently powered to detect any substantively significant changes in SJM.

To evaluate $\mathrm{H} 1$, that inequality increases system justification overall, we present simple differences-of-means in the levels of system justification across treatment and control conditions. Results from these $t$-tests are shown in Figure 2; the point estimates are presented with $95 \%$ confidence intervals. 
Table 1

Study 1 Moderation Analysis. Results of Linear Regression with an Interaction Between Income and the "High Inequality" Treatment

\begin{tabular}{lccc}
\hline & \multicolumn{3}{c}{ Dependent variable } \\
\cline { 2 - 4 } & $\begin{array}{c}\text { System } \\
\text { justification } \\
(1)\end{array}$ & $\begin{array}{c}\text { Confidence in } \\
\text { institutions } \\
(2)\end{array}$ & $\begin{array}{c}\text { Economic system } \\
\text { justification } \\
(3)\end{array}$ \\
\hline High inequality treatment & 0.009 & -0.013 & $-0.060^{* * *}$ \\
Household income (thousands USD) & $(0.025)$ & $(0.027)$ & $(0.021)$ \\
& 0.0001 & -0.0001 & $-0.0004^{* *}$ \\
High inequality * income & $(0.0002)$ & $(0.0002)$ & $(0.0002)$ \\
Constant & $-0.001^{* *}$ & -0.00002 & $0.001^{* *}$ \\
& $(0.0003)$ & $(0.0003)$ & $(0.0002)$ \\
Observations & $0.648^{* * *}$ & $0.623^{* * *}$ & $0.603^{* * *}$ \\
Adjusted $R^{2}$ & $(0.018)$ & $(0.019)$ & $(0.015)$ \\
Residual Std. error & 339 & 339 & 336 \\
F statistic & 0.031 & -0.005 & 0.017 \\
\hline
\end{tabular}

Note: ${ }^{*} p<0.1 ;{ }^{* *} p<0.05 ;{ }^{* * *} p<0.01$

On two of the three measures of system justification, the treatment produces entirely null results: the estimates for institutional trust (estimated effect $-0.01, p=$ 0.24 ) and economic system justification (estimated effect $-0.02, p=0.07$ ) do not reach conventional levels of statistical significance, and the estimated differences are small enough to be substantively meaningless.

The result for the third measure, the SJM scale, is a substantively small but statistically significant reduction in system justification after exposure to the highinequality treatment, (estimated effect $-0.03, p=0.03$ ). In other words, we find an effect in the opposite direction to the hypothesis. Exposing people to more inequality makes them slightly less likely to say the system is fair.

Turning to $\mathrm{H} 2$, we ask whether individual status moderates reactions to information about inequality, such that disadvantaged individuals respond with more system justification than advantaged individuals. We add an interaction between treatment condition and household income to the analysis. Table 1 presents the regression results. Across the three outcome variables, we see one negative and significant (but substantively small) coefficient on the interaction, one non-significant negative, and one positive significant coefficient (the latter is in the opposite direction to the hypothesized effect). We conclude that the findings across all three outcome variables are not consistent with the hypothesis that inequality is more effectively causing system justification among the poor than among the rich. Additional analysis of $\mathrm{H} 2$ can be found in Supplemental Information, where we also present two smaller, additional studies with substantively the same null results. 


\section{CONCLUSION}

We find no evidence that information about high inequality increases system justification. Across three different measures, in two cases the null hypothesis of no effect could not be rejected, and in one case we found an effect in the opposite direction to the hypothesis. Including interactions with household income does not reveal consistent moderation effects in the expected direction. In sum, we find no evidence to support the inequality-induced motivation hypothesis, and we find some small effects in the opposite direction of the hypothesis.

We do not think these null results are driven by treatment failure. Responses to our treatment check questions indicate that the treatments had the desired impact: when exposed to the "high inequality" treatment, respondents were significantly more likely (66\% compared to $40 \%$ in the low-inequality group) to agree that "Income inequality in the United States has increased dramatically over time," and significantly less likely to agree that "The share of total income of the very rich has not changed much over time in the United States" (18\% versus 38\%). Given this evidence of treatment effectiveness, in addition to the statistical power of our experiment and the precisely-estimated null point estimates shown in Figure 2 (as well as the extremely similar point estimates found in the two studies reported in the SI), we think it is unlikely that our null findings are simply a result of treatment failure or a lack of statistical power.

Further, we think this treatment captures one key way that inequality would shape system justification in the real world. Most Americans learn about economic inequality through media representations rather than direct personal experience (McCall, 2013), so a graphic reporting income inequality is a realistic representation of how members of the public are likely to learn about inequality. The particular measure of income inequality that we used, the Gini coefficient, is an abstract construct, but has previously been used in observational research to explore the relationship between system justification and inequality (Brandt, 2013; Napier and Jost, 2008), and graphs similar to our treatment appear in media stories about inequality. ${ }^{7}$ It is possible that inequality experienced in more personal ways could produce more system justification; whether it does is an open empirical question that our data do not address. However, given that media is an important source of information about inequality, it is important to know whether the inequality-induced motivation hypothesis holds for information acquired through graphs like our treatment.

In order to be sure that the null findings of one study were not simply a fluke or due to poor experimental design, we also ran two similar studies on convenience

\footnotetext{
${ }^{7}$ Graphs of over-time trends in inequality similar to the graphs used in our experimental treatment feature, for example, in "The Geography of U.S. Inequality", The New York Times, 6 September 2016, "The Rich and The Rest," The Economist, 13 October 2014; and "Facing Up to Income Inequality," The Boston Globe, 2 October 2016.
} 
samples, the detailed design and results of which are provided in the SI. These studies confirmed the null results in other samples, even when introducing an additional measure of system justification and a different inequality treatment. That we find consistently null results across several experiments and different operationalizations bolsters our confidence in the findings presented here.

We do not claim that these results undermine the existence of the SJM in general. A large body of work on system justification has established that people often consider inequality justified, and that system justification can serve important psychological purposes. We specifically focus on the inequality-induced motivation hypothesis: that the SJM becomes stronger when inequality is higher. We find no support for this hypothesis.

Increasing inequality in advanced societies has not led to corresponding increases in popular opposition to or concern about inequality. Given this context, we chose to study the inequality-induced motivation hypothesis because it posits an important mechanism that could explain this empirical pattern. Our results suggest that inequality-induced system justification is not a strong explanation for the lack of popular opposition to inequality.

\section{SUPPLEMENTARY MATERIAL}

To view supplementary material for this article, please visit https://doi.org/10. 1017/XPS.2018.2.

\section{REFERENCES}

Alesina, Alberto F. and Edward Glaeser. 2004. Fighting Poverty in the U.S. and Europe: A World of Difference. Oxford: Oxford University Press. (http://nrs.harvard.edu/urn-3: hul.ebookbatch.OXSCH_batch:osouk0199267669).

Brandt, Mark J. 2013. "Do the Disadvantaged Legitimize the Social System? A Large-Scale Test of the Status-Legitimacy Hypothesis." Journal of Personality and Social Psychology 104(5): 765-85. doi:10.1037/a0031751.

Brescoll, Victoria L., Eric Luis Uhlmann, and George E. Newman. 2013. "The Effects of System-Justifying Motives on Endorsement of Essentialist Explanations for Gender Differences." Journal of Personality and Social Psychology 105(6): 891-908. doi:10.1037/a0034701.

Day, Martin V. and Susan T. Fiske. 2017. Movin' On Up? How Perceptions of Social Mobility Affect Our Willingness to Defend the System. Social Psychological and Personality Science 8(3): 267-74. doi:10.1177/1948550616678454.

Franko, William W. 2016. "Political Context, Government Redistribution, and the Public's Response to Growing Economic Inequality.” Journal of Politics 78(4): 957-73. doi:10.1086/686025.

Franko, William W. 2017. "Understanding Public Perceptions of Growing Economic Inequality." State Politics \& Policy Quarterly 17(3): 319-48. doi:10.1177/ 1532440017707799. 
Hlavac, Marek. 2015. Stargazer: Well-Formatted Regression and Summary Statistics Tables. Cambridge, USA: Harvard University. (http://CRAN.R-project.org/package= stargazer). R package version 5.2.

Johnson, India R. and Fujita, Kentaro. 2012. "Change We Can Believe in: Using Perceptions of Changeability to Promote System-Change Motives Over SystemJustification Motives in Information Search." Psychological Science 23(2): 133-40. doi:10.1177/0956797611423670.

Jost, John T. and Mahzarin R. Banaji. 1994. "The Role of Stereotyping in SystemJustification and the Production of False Consciousness." British Journal of Social Psychology 33: 1-27.

Jost, John T., Sally Blount, Jeffrey Pfeffer, and Györgi Hunyady. 2003. "Fair Market Ideology: Its Cognitive-Emotional Underpinnings." Research in Organizational Behavior 25: 53-91.

Jost, John T. and Kay, Aaron C. 2005. "Exposure to Benevolent Sexism and Complementary Gender Stereotypes: Consequences for Specific and Diffuse Forms of System Justification." Journal of Personality and Social Psychology 88(3): 498-509. doi:10.1037/00223514.88.3.498.

Jost, John T. and Erik P. Thompson. 2000. "Group-Based Dominance and Opposition to Equality as Independent Predictors of Self-Esteem, Ethnocentrism, and Social Policy Attitudes Among African Americans and European Americans." Journal of Experimental Social Psychology 36(3): 209-232. doi:10.1006/jesp.1999.1403.

Jost, John T., Mahzarin R. Banaji, and Brian A. Nosek. 2004. "A Decade of System Justification Theory: Accumulated Evidence of Conscious and Unconscious Bolstering of the Status Quo.” Political Psychology 25(6): 881-919.

Kay, Aaron C. and John T. Jost. 2003. "Complementary Justice: Effects of "Poor but Happy" and "Poor but Honest" Stereotype Exemplars on System Justification and Implicit Activation of the Justice Motive." Journal of Personality and Social Psychology 85(5): 823-37. doi:10.1037/0022-3514.85.5.823.

Kay, Aaron C., Danielle Gaucher, Jennifer M. Peach, Kristin Laurin, Justin Friesen, Mark P. Zanna, and Steven J. Spencer. 2009. "Inequality, Discrimination, and the Power of the Status Quo: Direct Evidence for a Motivation to See the Way Things Are As the Way They Should Be." Journal of Personality and Social Psychology 97(3): 421-34. doi:10.1037/a0015997.

Kelly, Nathan J. and Peter K. Enns. (2010). "Inequality and the Dynamics of Public Opinion: The Self-Reinforcing Link Between Economic Inequality and Mass Preferences." American Journal of Political Science 54(4): 855-70. doi:10.1111/j.15405907.2010.00472.x.

Kenworthy, Lane and Leslie McCall. 2008. "Inequality, Public Opinion and Redistribution." Socio-Economic Review 6(1): 35-68. doi:10.1093/ser/mwm006.

Laurin, Kristin, Steven Shepherd, and Aaron C. Kay. 2010. "Restricted Emigration, System Inescapability, and Defense of the Status Quo: System-Justifying Consequences of Restricted Exit Opportunities. Psychological Science 21(8): 1075-82. doi:10.1177/0956797610375448.

Luttig, Matthew. 2013. “The Structure of Inequality and Americans' Attitudes Toward Redistribution." Public Opinion Quarterly 77(3): 811-21. doi:10.1093/poq/nft025.

McCall, Leslie. 2013. The Undeserving Rich: Beliefs about Inequality, Opportunity, and Redistribution in American Society. Cambridge: Cambridge University Press.

McCall, Leslie. 2016. Political and Policy Responses to Problems of Inequality and Opportunity: Past, Present, and Future. Cham: Springer International Publishing, 41542. doi:10.1007/978-3-319-25991-8_12. 
McCall, Leslie, Derek Burk, Marie Laperrire, and Jennifer A. Richeson. 2017. "Exposure to Rising Inequality Shapes Americans' Opportunity Beliefs and Policy Support." Proceedings of the National Academy of Sciences of the United States of America 114(36): 9593-8. doi:10.1073/pnas.1706253114.

Meltzer, Allan H. and Scott F. Richard. 1981. "A Rational Theory of the Size of Government." Journal of Political Economy 89(5): 914-927.

Mishel, Lawrence and Nicholas Finio. 2013. "Earnings of the Top 1.0 Percent Rebound Strongly in the Recovery." (http://www.epi.org/publication/ ib347-earnings-top-one-percent-rebound-strongly).

Napier, Jaime L. and John T. Jost. 2008. "Why are Conservatives Happier than Liberals?" Psychological Science 19(6): 565-72. doi:10.1111/j.1467-9280.2008.02124.x.

Pandey, Anshul Vikram, Katharina Rall, Margaret L. Satterthwaite, Oded Nov, and Enrico Bertini. 2015. "How Deceptive are Deceptive Visualizations?" Proceedings of the 33rd Annual ACM Conference on Human Factors in Computing Systems - CHI '15, 146978. doi:10.1145/2702123.2702608.

Saez, E. 2013. "Striking it Richer: The Evolution of Top Incomes in the United States. (Updated with 2012 preliminary estimates)." (https://elsa.berkeley.edu/ saez/ saez-UStopincomes-2012.pdf).

Schröder, Martin. 2017. “Is Income Inequality Related to Tolerance for Inequality?” Social Justice Research 30(1): 23-47.

Solt, Frederick. 2009. "Standardizing the World Income Inequality Database." Social Science Quarterly 90(2): 231-42.

Trump, Kris-Stella. 2017. "Income Inequality Influences Perceptions of Legitimate Income Differences.” British Journal of Political Science doi:10.1017/S0007123416000326.

Trump, Kris-Stella and Ariel White. 2017. "Replication Data For: Does Inequality Beget Inequality? Experimental Tests of the Prediction that Inequality Increases System Justification Motivation.” doi:10.7910/DVN/SWV9GJ.

Wakslak, Cheryl J. and Patrick Bauer. 2011. "Spreading Rationalization: Increased Support for Large-Scale and Small-Scale Social Systems Following System Threat." Social Cognition 29(2): 288-302. 